\title{
NATURAL GAS PIPELINES, PEAK LOAD PRICING AND THE FEDERAL POWER COMMISSION
}

\author{
SIMON M. LORNE*
}

The pricing structure appropriate for a firm which faces a peak load problem, ${ }^{1}$ as do most natural gas pipeline companies, has been subjected to a thorough examination in the economic literature over the past fifteen years. ${ }^{2}$ Unfortunately, that examination has been almost entirely theoretical, and has not been applied to the concrete problems faced by the Federal Power Commission in its task of regulating gas pipeline rates; and the FPC, in developing a body of law which has, at best, a vague relation to a rational basis, has demonstrated its need for the assistance of experts. ${ }^{3}$ However, the FPC does not bear sole responsibility for this irrational development, since the

\footnotetext{
* A.B. 1967, Occidental College; J.D. 1970, University of Michigan; Member of the California Bar. The author wishes to express his appreciation to Professor Peter O. Steiner of the faculty of Economics of the University of Michigan and of the University of Michigan Law School, for his comments on earlier drafts of this article. The author, of course, accepts all responsibility for any errors.

1. A peak load problem exists when a product is demanded in more than one time period and the quantity demanded during each period is different although the price remains constant. Steiner, Peak Loads and Efficient Pricing, 71 Q.J. EcoN. 585, 587 (1957).

THE FOLLOWING HEREINAFTER CITATIONS ARE USED IN THIS ARTICLE:

P. Garfield \& W. Lovejoy, Public Utility Economics (1964) [hereinafter cited as GARFIELD \& LOVEJOY];

Steiner, Peak Load Pricing Revisited, in I968 Conference of Public Utilities INSTItute, Proceedings (Trebing ed. 1971) [hereinafter cited as Steiner, Proceedings];

Steiner, Peak Loads and Efficient Pricing, 7I Q.J. Econ. 585 (1957) thereinafter cited as Steiner].

2. See, e.g., Steiner, Proceedings; Buchanan, Peak Loads and Efficient Pricing: Comment, 80 Q.J. Econ. 463 (1966); Gabor, Peak Loads and Efficient Pricing: Further Comment, 80 Q.J. EcoN. 472 (1966); Littlechild, Marginal Cost Pricing with Joint Costs, 80 Econ. J. 323 (1970); Pressman, A Mathematical Formulation of the Peak-Load Pricing Problem, 1 BeLL J. ECoN. \& MGr. Scr. 304 (1970); Steiner 585; Steiner, Peak Loads and Efficient Pricing: Reply, 72 Q.J. Econ. 465 (1958); Williamson, Peak Load Pricing and Optimal Capacity, 56 AM. Econ. Rev. 810 (1966). Indeed, one of the current points of debate appears to be whether the solution to the problem is of relatively recent or of ancient vintage. Compare Demsetz, Has the Peak Load Problem Been Solved? (1967, unpublished), cited in Littlechild, supra, at $324 \mathrm{n} .1$ with Steiner, Proceedings and Littlechild, supra, 324 n.1.

3. As to the general need for greatcr use of economic expertise by regulatory agencies, see Donahue, Book Review, $70 \mathrm{MiCH}$. L. Rev. 195 (1971). An interesting contrast with the view expressed by Professor Donahue is found in Brown, The Values \& Value of Economists, 15 AM. ECON. 47 (1971).
} 
application of economic theory to pipeline rate regulation is complicated, and a thoroughly satisfactory solution is not feasible under existing statutory constraints. Nonetheless, because it is better to approach perfection than to ignore it, a legal-economic analysis of pipeline rate regulation is appropriate. While the resolution of all the regulatory difficulties in this area might require statutory changes, there are a significant number of interim steps which can be taken to narrow the gap between economic theory and regulatory practice.

The solution to the problem of peak load pricing, that is, the proper method for determining prices for peak and off-peak users, was succinctly presented by Professor Steiner in $1957^{4}$ and, before that, by Boiteaux in France. ${ }^{5}$ While the theory indicates a possible solution to the major problems of gas pipeline rate regulation, the FPC has ignored it. The limited discussion which follows is not intended as a critical analysis of the Boiteaux-Steiner solution, but merely as a demonstration of the theory's usefulness.

\section{The Theory of Peak Load Pricing}

There are four assumptions which simplify the Boiteaux-Steiner analysis. First, it is assumed that the cost of obtaining a unit of production capacity ${ }^{6}$ (hereinafter represented by " $B$ " dollars) does not vary with the number of units of capacity obtained, and that one unit of capacity can be used to produce one unit of output in any or all periods of operation. Second, it is assumed that production capacity can be increased without incurring diseconomies by an amount so small that the increased capacity is sufficient to produce only one additional unit of output in each period of operation. Third, it is assumed that the cost of using existing capacity to produce output remains constant for each unit of output (hereinafter represented by "b" dollars per unit of output). Finally, it is assumed that the same price per unit must be charged to all purchasers of output making purchases in the same time period. However, the price charged during

4. Steiner.

5. Boiteaux, La Tarification des demandes en pointe, 58 RevUE Generale DE L'ELECTRICITÉ 321 (1949). Boiteaux' work was not available in English until 1960, Peak Load Pricing, 33 J. Bus. 157 (1960), and Steiner's independently arrived at solution is therefore commonly considered the foundation of the solution.

6. It is important to observe that the cost of a unit of capacity cannot be equated with the cost of a unit of output. Capacity measures not output, but rather the ability to produce output in a given period of time. 
a particular time period may differ from the price charged during a different time period. ${ }^{7}$

Operating within these assumptions, which are useful but not essential to the analysis ${ }^{8}$ Steiner and Boiteaux demonstrate a method for determining the price of the commodity during different time periods in such a manner that the resources devoted to the production and sale of the commodity will be used optimally.

Initially, "price" in the context of the peak load problem does not mean the price at which a unit of output is sold, but rather means the total amount received from the sale of all units of output which are produced by a given unit of capacity. Since a unit of capacity can produce output during each time period, the total amount received in all periods from output produced by any unit of capacity equals the "price" for that unit of capacity. ${ }^{9}$

In Figure 1, it is assumed that there are three time periods of price

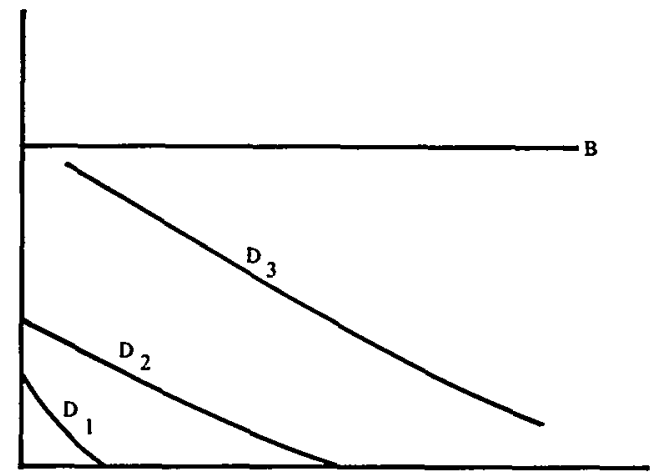

FIGURE

7. Although the assumptions upon which the theory is based are simplifications, relaxing them does not impair the validity of the model. See Steiner, ProceEdings. Rather, it merely makes the analysis more complex and renders the graphical depiction much less satisfactory.

8. Id.

9. For example, assume that there are two relevant time periods, day and night. If the nth unit of capacity is used to produce output which is sold for $y_{1}$ dollars during the day and for $\mathrm{y}_{2}$ dollars during the night, then the total output produced by the nth unit of capacity was sold for a "price" of $y_{1}+y_{2}$ dollars. The demands for output during different time periods are 
equal duration; ${ }^{10}$ the demand curves for the output produced by units of capacity during those three periods are represented by lines $D_{1}, D_{2}$ and $D_{3}$. If the product is gas and the three periods are the three eighthour periods in a day, then any given point on the $D_{1}$ curve represents the amount of capacity which will be needed to produce the output which gas users will demand, at the price which corresponds with that point, during the first eight hours of the day and similarly, $\mathrm{D}_{2}$ and $D_{3}$ indicate the demand for capacity during the second and third eight-hour periods. The base line of Figure 1 is $b$-the level of operating costs per unit of output - and $D_{1}, D_{2}$ and $D_{3}$, none of which extends below $b$, represent the demand at prices in excess of operating costs. 1t is assumed that if price is below operating costs during one or more periods, then the capacity will not be operated uuring that period. The level represented by $B$ is the cost per unit of obtaining new capacity; because this cost is by assumption constant, the marginal cost $(\mathrm{MC})$ of new capacity equals its average cost (AC).

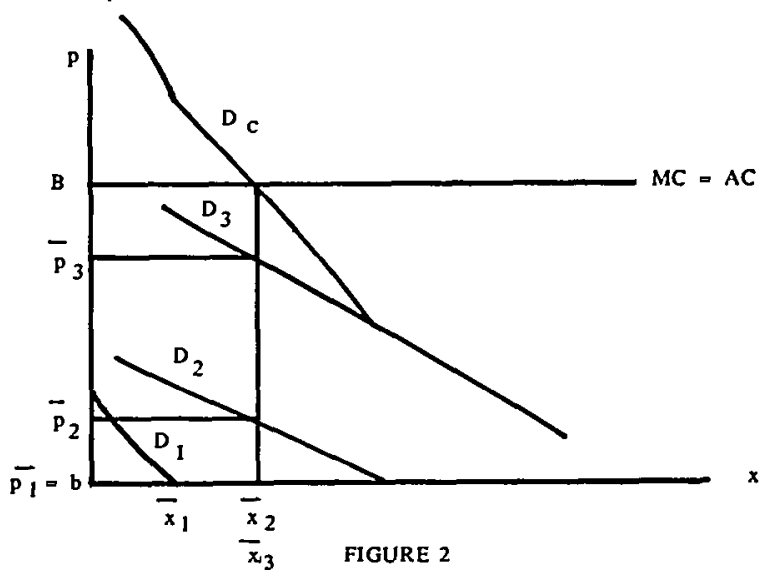

thus complementary, in the sense that they do not compete with each other for the same output; rather, each determines how much will be paid for the output of one unit of capacity produced at different times, and their total determines how much will be paid for all the output produced by a unit of capacity throughout one cycle of the relevant periods of time.

10. It should not be thought that there must be any specific numbers of periods, such as three eight-hour periods. There might just as easily be twenty-four one-hour periods. See Steiner, Proceedings. 
Because demand curves $D_{1}, D_{2}$ and $D_{3}$ represent the demand for capacity in each of three separate periods and are complementary, the total demand for capacity is the vertical sum of the demand curves for each period-the vertical sum for each level of total capacity equals the amount that will be paid for the output produced by one unit of capacity during a 24 hour day. Thus, in Figure 2, Dc represents the total demand for capacity-the vertical sum of $D_{1} . D_{2}$ and D3.

Under the Boiteaux-Steiner approach, the appropriate prices to charge are $\bar{p}_{1}$ during period one, $\overline{\mathrm{p}}_{2}$ during period two, and $\overline{\mathrm{p}}_{3}$ during period three. ${ }^{11}$ The amount of capacity used during periods two and three will be the same, $\bar{x}_{2}=\bar{x}_{3}$, and each represents the full use of capacity. Both the $D_{2}$ users and $D_{3}$ users are "peak" users in the sense that they use capacity to the fullest extent. although $D_{3}$ is clearly "stronger" than $D_{2}$. During period one, $\bar{x}_{1}$ units of capacity should be used, for if output were at any greater level, the proceeds from its sale would be less than the operating cost of producing it.

The most important characteristics of this model are that the producing firm will have that amount of physical capacity which corresponds to the optimal use of resources, the firm's capacity will be efficiently utilized, and the full social cost of the resources used will be covered by revenues. If the maximum capacity were less than $\bar{x}_{2}$ and $\bar{x}_{3}$, people willing to pay the cost of producing additional output would be unable to purchase the product. Since the excess of consumer satisfaction over the cost of resources devoted to production, represented by the area between the demand curve, Dc. and the average cost curve, $\mathrm{AC}$, is to be maximized, ${ }^{12}$ it follows that if capacity is less than $\bar{x}_{2}$ and $\bar{x}_{3}$, the potential social benefit of an additional unit will be greater than the cost of providing it. At a capacity greater than $\bar{x}_{2}$ and $\bar{x}_{3}$, however, the revenues obtained from the use of the capacity would not be sufficient to pay the cost of creating it. Thus, $\bar{x}_{2}$ and $\bar{x}_{3}$

11. The welfare proposal which forms the basis of the Steiner-Boiteaux analysis is that it is desirable to maximize the excess of expressed consumer satisfaction over the cost of resources devoted to production. See Steiner 596. This requires that the output be that which would be produced if price were equal to marginal cost. In the case of a profit-maximizing monopolist, of course, price would be set in such a manner that the quantity produced and sold would be at the level at which marginal cost equals marginal revenue. The difference in output between that which is socially optimal and that which results from monopolistic profit maximization is what is usually thought of as the resource misallocation evil of monopoly.

12. See note II supra. 
indicate the preferable output capacity - there is enough output that all consumers willing to pay the cost of capacity are able to purchase the product, but the amount of potential output, with full utilization of capacity, does not result in a price so low as to result in a loss.

The optimal price schedule indicated by Figure 2 also leads to an efficient utilization of capacity, for capacity is used, during all periods, to the maximum feasible extent. During period one, capacity is used to the extent that buyers are willing to pay the cost of operating the facilities. During the second and third periods, the total capacity is in use. The prices $\overline{\mathrm{p}}_{2}$ and $\overline{\mathrm{p}}_{3}$ are, it should be noted, proportionate to the strength of the demand curves from which they are derived. ${ }^{13}$ Thus, the Boiteaux-Steiner solution to the problem of peak load pricing is the correct solution in the sense that it leads' not only to the construction of the most efficient amount of capacity, but also leads to the most efficient use of that capacity.

Although the FPC, like most regulatory agencies, is not always preoccupied with efficiency, the manner in which the economic literature has been ignored by those who deal closely with the FPC is surprising. As a result, there are now two entirely separate bodies of literature, one dealing with economic theory and the other with the FPC regulation of gas pipeline rates. The interaction between the two, although necessary, has thus far been nonexistent.

\section{The Peak Load Problem and the Natural Gas PIPELINE INDUSTRY}

Before an analysis of FPC regulation can be meaningful, it is necessary to understand some aspects of the basic structure of the gas pipeline industry. The industry differs significantly from the Boiteaux-Steiner model in terms of the relevant cost curves. Typically, within the relevant range of pipeline sizes, the cost per unit of pipeline capacity decreases as the total capacity increases-the typical firm faces both a decreasing average cost function and a decreasing marginal cost function. ${ }^{14}$ Firms with a relatively large pipeline capac-

13. In economic terms, the fact that the price varies solely with respect to demand leads to the conclusion that it is discriminatory. Steiner 590. But cf. Williamson, supra note 2. It is probably not, however, within the prohibition of 15 U.S.C. $\S 717 \mathrm{c}(\mathrm{b})(1970)$, since it is neither "undue" nor "unreasonable." Cf. Michigan Consol. Gas Co. v. FPC, 203 F.2d 895 (3d Cir. 1953); Michigan Consol. Gas Co. v. Panhandle E. Pipeline Co., 173 F.2d 784 (6th Cir. 1949).

14. See P. Garfield \& W. Lovejoy, Public Utility Economics 175 (1964). If average cost is decreasing as output increases, it necessarily follows that marginal cost is less that average cost, for if the cost of the avcrage unit is decreasing, the cost of the "last" unit added must be less than what was previously the avcrage cost. 
ity are able to provide gas at a lower per unit cost than firms with a relatively small pipeline capacity. ${ }^{15}$ These cost conditions are graphically depicted in Figure 3 , in which $\mathrm{p}$ represents price, $\mathrm{x}$ represents quantity, the average cost function is indicated by $A C$, the marginal cost function by $M C$, and the demand curve by $D D$.

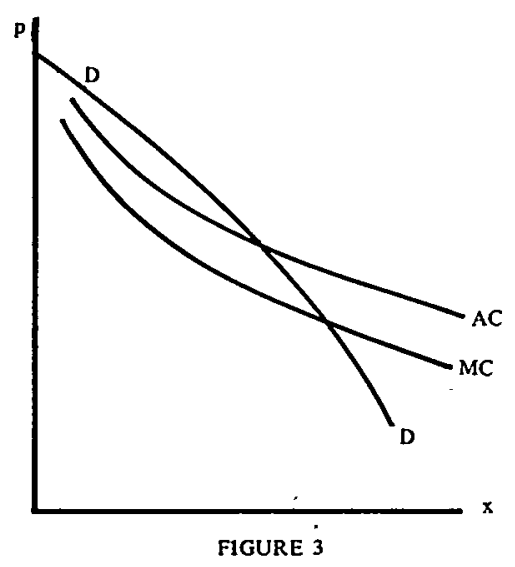

Since the marginal and the average cost curves do not intersect the demand curve at the same point, one must decide whether to set price equal to marginal cost or equal to average cost. ${ }^{16}$ If the former is chosen, each customer will pay the cost of providing his service, but average costs will not be covered and it will be necessary to subsidize the company. If the latter is selected, there will be people who are willing to pay the actual cost of providing them with service but who are unable to obtain service because they are unwilling to pay the higher price which is charged. A third possibility, which avoids this choice, allows the firm to obtain additional revenues from some con-

15. The conditions are therefore present which give rise to "natural monopoly." C. AlleN, J. Buchanan \& M. Colberg, Prices, Income and Public Policy 339-41 (1954); W. Haynes, Managerial Economics 410-11 (1963); R. LiPSey \& P. SteIner, Economics 357-58 (1968).

16. See generally. Hotelling, The General Welfare in Relation to Problems of Taxation and of Railway and Utility Rates, 6 EcONOMETRICA 242 (1942); Vickrey, Some Implications of Marginal Cost Pricing for Utilities, 45 AM. Econ. REv. 605 (1955). 
sumers in order to offset losses resulting from sales at marginal cost prices to other purchasers. But to suggest that such an approach provides a solution to the pricing problem is misleading, for it is, in reality, nothing more than a disguised subsidy paid by one group of customers rather than by the government. Such a policy may be justified if there is sufficient reason for determining that the subsidizing group "should" perform that function, but it is not inherently desirable. ${ }^{17}$

The second major difference between the typical natural gas pipeline company and the company assumed to exist for purposes of the Boiteaux-Steiner model is that demand during one period must be represented by two curves instead of by one. Because the Natural Gas Act limits the jurisdiction of the FPC to the "sale in interstate commerce of natural gas for resale for ultimate public consumption," 18 it is desirable for many purposes to differentiate between the demand for "jurisdictional" gas - sold for resale - and the demand for "nonjurisdictional" gas-sold for direct consumption by the purchaser. Typically, a very high percentage of gas purchases during peak periods will be jurisdictional, made by gas utility companies for distribution to their customers. Such companies usually contract with the pipeline company for "firm" service-service which is guaranteed to be available at all times.

Purchasers during periods of relatively weaker demand, however, usually purchase "interruptible" service-their supply of gas will be interrupted whenever the pipeline capacity must be devoted to the service of firm purchasers - and the prices they pay are relatively low. Interruptible service is commonly purchased by both jurisdictional and non-jurisdictional users. ${ }^{19}$ For example, some utility companies,

17. None of these three approaches has been clearly adopted by the FPC. There is no outright subsidy paid by the government to pipeline companies, and the probable goal of FPC regulation has been to set prices equal to average cost. See text following note 61 infra. Since the FPC approaches rate setting from a different conceputal framework, the question never arises in these terms.

18. 15 U.S.C. $\& 717$ (b) (1970). The Act also provides for jurisdiction over "the transportation of natural gas in interstate commerce . . . and . . . natural-gas companies cngaged in such transportation, or sale." Id. It has long been settled that the FPC has no power to regulate the price of "direct" sales-that is, sales directly for consumption and not for resale. See, e.g., FPC v. Transcontinental Gas Pipe Line Corp., 365 U.S. 1 (1961). The reason for this bifurcation appears to be that competition in the non-jurisdictional market renders regulation unnecessary. See GARFiELD \& LoveJOY 174.

19. See GARFiELD \& Lovejoy 175-78. It is useful to observe at this point that interruptible users pay only commodity charges (as discussed at text accompanying note 25 infra), whilc firm 
who purchase at FPC-determined rates, will purchase gas during offpeak periods, at interruptible rates, and store it for distribution during peak periods. On the other hand, some non-jurisdictional purchasers, such as electrical utility companies and industrial plants, which are equipped to use different types of fuel, will buy gas only during periods when it is available at the lower, interruptible prices. Since some of such interruptible sales are jurisdictional, and subject to FPC rates, while others are not, it is analytically useful to distinguish between the jurisdictional and the non-jurisdictional demand for the output that results from the use of capacity during periods of relatively weaker demand.

During any given off-peak period, the demand for nonjurisdictional gas must compete for pipeline capacity with that for jurisdictional gas. A unit of pipeline capacity can be used to supply either a jurisdictional or a non-jurisdictional user, but not both. Thus, the situation is inherently different from that discussed earlier in which different time periods were being analyzed. There the demands on capacity were noncompetitive, since one unit of capacity could be used to supply one consumer during one period and another consumer during another period. ${ }^{20}$ In that earlier discussion, it was observed that the total demand for capacity could be represented by the vertical sum of the demand curves applicable to each period, since the total price realized from the use of capacity during all the periods was the sum of the prices realized in each period. Here, however, the concern is with different users during one time period. The total demand for that period is the horizontal sum of the demand curves of each consumer-for the total amount demanded during the off-peak period, at any given price, is the sum of the demands of (not the sum of the prices that would be paid by) jurisdictional and non-jurisdictional users during that period at that price. It follows that the total demand

users pay both commodity charges and demand charges (id.). To the extent that commodity charges approximate " $b$ " dollars-which the definition of "commodity costs" suggests they should approximate, but which in practice they do not-the pricing scheme for firm (peak) and interruptible (off-peak) users would be appropriate, as Professor Steiner has observed in private correspondence with the author. In that situation, firm users would pay, generally, $\mathrm{B}+\mathrm{b}$ dollars and interruptible users would pay b dollars. However, as is discussed infra, "commodity costs" are not equal to $\mathrm{b}$, but are equal to b plus some portion of $\mathrm{B}$. If interruptible users, in fact, used capacity to the fullest extent, and therefore were properly characterized as peàk users (the $\mathrm{D}_{2}$ users in Figure 2), such a pricing scheme might still be appropriate, but it is clear that any such identity between the actual scheme and the ideal would be purely coincidental.

20. See text following note 8 supra. 
for capacity during both peak and off-peak periods is represented by the horizontal sum of the jurisdictional and non-jurisdictional demand during the off-peak periods, and the vertical sum of that horizontal sum plus the peak demand for capacity. That three-part sum is demonstrated in Figure 4, in which $D_{1}$ represents the nonjurisdictional demand for off-peak capacity, $\mathrm{D}_{2}$ the jurisdictional demand for off-peak capacity, and $\mathrm{D}_{\mathrm{C} 1}$ the horizontal sum of $\mathrm{D}_{1}$ plus $D_{2}$. $D_{3}$ represents the demand for peak capacity (which is, by assumption, an entirely jurisdictional demand), and $D_{C} 2$ the total demand for capacity - that is, the vertical sum of Dc1 plus D3.

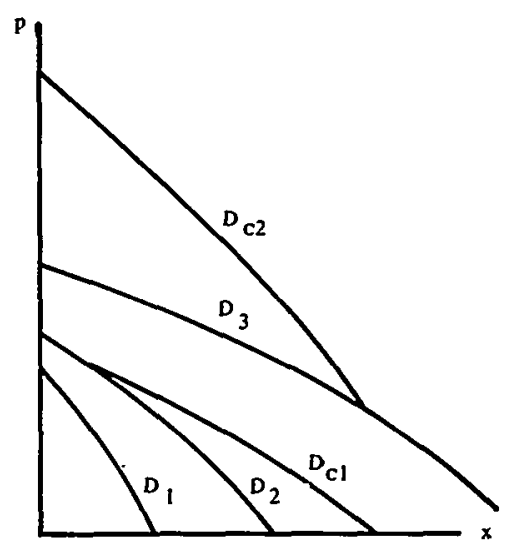

FIGURE 4

In Figure 5, Figure 4 has been superimposed on Figure 3, in order to present, in rough approximation, the full model which is faced by the FPC. Horizontal and vertical lines have been added in appropriate places to indicate the pricing and output consequences of a decision to impose either average cost pricing or marginal cost pricing on the hypothetical firm which is represented by these functions. If average cost pricing is used, the appropriate amount of capacity for the firm to build and to operate during each period is $\overline{\mathrm{x}}_{3 \mathrm{~A}}$. During the period of relatively weaker demand, $\bar{x}_{1_{A}}$ units of capacity will be devoted to 
non-jurisdictional sales and $\overline{\mathrm{x}}_{2 \mathrm{~A}}$ units will be devoted to the production of output for jurisdictional sales. Since the solution in Figure 5 requires the full use of capacity during both time periods, the situation depicted by Figure 5 is that of the "shifting peak" in which full capacity is used during both periods, but the Boiteaux-Steiner analysis demands different prices for each group. In Figure 5, the prices charged the consumer classes for their use of capacity are represented by $\overline{\mathrm{p}}_{\mathrm{A}}, \overline{\mathrm{p}}_{2 \mathrm{~A}}$, and $\overline{\mathrm{p}}_{3 \mathrm{~A}} \cdot{ }^{21}$ lf marginal cost pricing is used, requiring that a subsidy be paid to the pipeline company, the relevant points of capacity construction and use, and the relevant prices, are indicated by, respectively, $\overline{\mathrm{x}}_{3 \mathrm{M}}, \overline{\mathrm{x}}_{1 \mathrm{M}}, \overline{\mathrm{x}}_{2 \mathrm{M}}, \overline{\mathrm{p}}_{1 \mathrm{M}}, \overline{\mathrm{p}}_{2 \mathrm{M}}$ and $\overline{\mathrm{p}}_{3 \mathrm{M}}$.

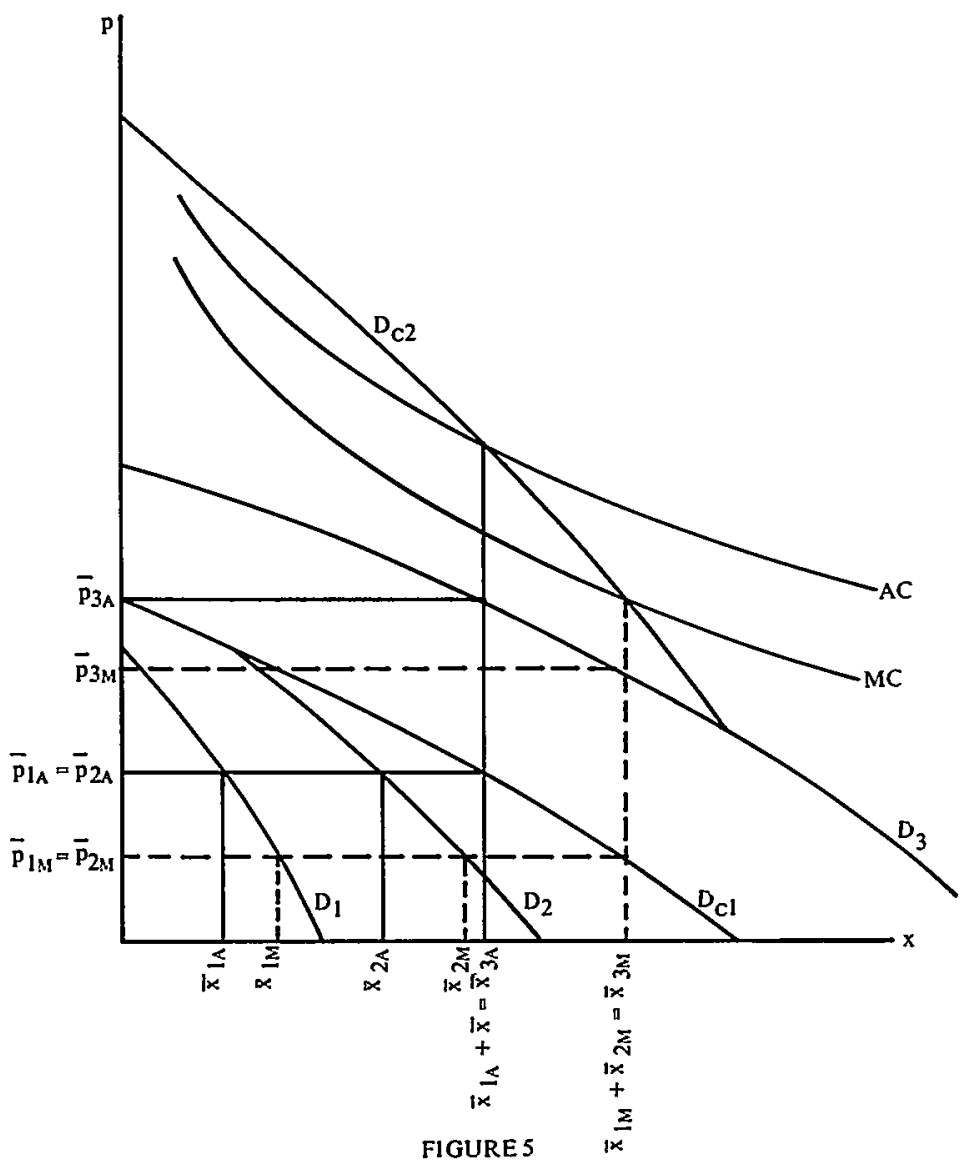

21. It is assumed here that $\mathrm{p}_{1 \mathrm{~A}}$ equals $\mathrm{p}_{2 \mathrm{~A}}$ That assumption is made here for the same reason that it was earlier assumed that prices to different users during one time period must be 


\section{The fPC Response to the Peak Load Problem:}

\section{AtLantic SEABoard}

\section{The Atlantic Seaboard Formula}

In Atlantic Seaboard Corp. ${ }^{22}$ the FPC announced the approach it has followed, at least nominally, for some twenty years. ${ }^{23}$ The first step in the Atlantic Seaboard approach requires allocating costs between jurisdictional and non-jurisdictional sales. This cost allocation is fundamental to FPC rate setting, because the FPC adheres to the view that its function is to prevent the acquisition of monopoly profits on jurisdictional sales. Since that task is viewed as the raison d'etre of regulation. the simplest method of regulating properly requires no more than setting jurisdictional prices by reference to jurisdictional operating costs plus an appropriate return on invested capital. ${ }^{24} \mathrm{Mo}-$ nopoly profits - an excessive return on invested capital-are necessarily eliminated since the return is prevented from being excessive. To accept such an approach requires, of course, a great deal of confidence in the agency's ability accurately to measure and segregate jurisdictional costs, for if the recovery allowed for those costs is excessive a monopoly profit will be built into the rates set by the FPC. Apparently, the FPC has that self-confidence, for it has maintained this pattern of setting rates.

An essential element of the. Atlantic Seaboard approach is the distinction between "commodity costs," which are the only charges which interruptible users pay, and "demand costs," which firm users pay in addition to commodity costs. In theory, the two types of costs correspond to, respectively, operating costs and capacity costs, as

identical. In reality, however, it may be possible to charge different prices to different users during one time period.

22. 11 F.P.C. 43, 94 P.U.R. (NS) 235 (1952), remanded on other grounds, 200 F.2d 108 (4th Cir. 1952).

23. It is perhaps not surprising that an erroneous analysis of the peak load problem was endorsed in Atlantic Seaboard, for the Boiteaux solution, see note 3 supra, was then buried in an obscure French journal, and Steiner's analysis was five years in the future. Howcver, the continued adherence to the Atlantic Seaboard formula is mueh more difficult to justify, for it is now fifteen years since Steiner's solution appeared and more than ten years since the Boiteaux analysis was transiated.

24. GARFIELD \& LOVEJOY 180-84. The process of rate setting by refcrence to costs is not. however, desirable. See text accompanying note 50 infra. 
those terms are used in the Boiteaux-Steiner model. ${ }^{25}$ Unfortunately. however, the distinction between the two types of costs was badly blurred in Atlantic Seaboard and has not since been clarified by the FPC. As a result, some confusion surrounds the conceptual distinction which appears throughout the FPC decisions.

The FPC, in examining a rate case, first separates variable costs as generally attributable to commodity charges, and the propriety of that attribution is not a matter of great dispute. Then, however, the FPC calculates the total of "fixed" costs, including depreciation, return on capital, and all other non-variable costs, and allocates those fixed costs between commodity costs and demand costs on a fifty-fifty basis. If it is assumed that the relevant demand curves are such that there is at least one period of clear off-peak demand-that is, that there is at least one group such as the $D_{1}$ users in Figure 2-the Atlantic Seaboard allocation of fixed costs leads to a charge to those (interruptible) users which necessarily includes an element of capacity costs even though their demand has no impact at all on the amount of capacity constructed. In any event, it is apparent that the portion of capacity costs which each jurisdictional user must pay under Atlantic Seaboard bears no necessary relation to the portion which the Boiteaux-Steiner approach would impose. If, for example, offpeak users use 25 percent of the total amount of gas used during any specific period, they will pay 25 percent of the total of all commodity charges, and will also pay 25 percent of 50 percent ( 12.5 percent) of the fixed costs since 50 percent of the fixed costs are allocated to the commodity charge. Peak users, who use 75 percent of the gas and who therefore pay 75 percent of the commodity costs, will pay 75 percent of 50 percent ( 37.5 percent) of the fixed costs, in accordance with the commodity charges which they pay; they will also pay the entire other 50 percent of the fixed costs allocated to the demand costs, which only they pay. Thus the percentage of fixed costs paid by peak users is 87.5 percent. Nowhere in the calculation is the contribution of the separable demand curves to the cumulative demand curve considered.

Once costs are allocated between commodity costs and demand costs, the FPC then seeks to allocate each of these costs between jurisdictional and non-jurisdictional sales. The reason for this alloca-

25. 11 F.P.C. 43, 52-53, 94 P.U.R. (NS) 235, 244 (1952). 1t has been suggested that even the fundamental determination of which costs are fixed and which are variable was inappropriately made in Atlantic Seaboard. See, e.g., GARFIELD \& LOVEJOY 182-83. 
tion is simply that the FPC sets rates only for jurisdictional sales, and these rates must not reflect any of the costs of supplying nonjurisdictional users. First, commodity costs are allocated in the proportion of jurisdictional to non-jurisdictional sales during the entire test year. ${ }^{26}$ Demand costs are allocated between jurisdictional and non-jurisdictional sales on the basis of the three-day peak demand for gas during the test year. ${ }^{27}$ Thus, variable costs are allocated on the basis of the costs incurred over a full year, while capacity costs are allocated on the basis of use during a three-day peak period.

The FPC approach is thus based on finding an "accurate" allocation of costs between the different markets for gas. The BoiteauxSteiner approach is based on finding the price which will lead to construction of the most efficient size pipeline and to the most efficient utilization of that pipeline. While the Boiteaux-Steiner approach uses costs in its analysis, it recognizes that the relationship between costs and economically efficient prices is considerably more intricate than does the FPC's approach.

Given this background, it is probably not surprising that the Atlantic Seaboard formula has been sharply criticized and that the FPC has retreated somewhat from the stance which it took in that case. Unfortunately, however, the FPC retreat has not been an organized one, and no clear doctrine has yet been accepted by the FPC to replace Atlantic Seaboard.

\section{Modifications in the Seaboard Doctrine}

The FPC's first opportunity to modify Atlantic Seaboard came in the same year that it was decided, 1952. In Northern Natural Gas $\mathrm{Co}^{28}$ the argument was made that demand costs should be allocated between jurisdictional and non-jurisdictional sales on a basis other than the three days of greatest sustained demand. The basis for the argument was that "true" demand for capacity would be better measured by the three coldest days of the year. Inasmuch as the suggested modification would have led to a greater allocation of costs to jurisdictional sales, it would have meant that regulated prices would have been increased to absorb the "additional" costs. However the FPC

26. GARFIELD \& LOVEJOY 183.

27. Id. at 184 .

28. 11 F.P.C. 174, 95 P.U.R. (NS) 289 (1952), affd sub nom. State Corp. Comm'n v. FPC, 206 F.2d 690 (8th Cir. 1953), cert. denied, 346 U.S. 922 (1954). 
adopted the view, which was probably sound, that the modification was suggested for no reason other than to justify a rate increase, and refused to accept the suggestion. ${ }^{29}$ Some sixteen years later this issue arose again, and the FPC indicated that in appropriate cases a "weather normalization adjustment" would be allowed. ${ }^{30}$ While some commentators have criticized the selection of the three-day peak sustained demand, ${ }^{31}$ the availability of some adjustment is probably desirable if the Atlantic Seaboard formula is to be maintained, and the FPC has indicated that an adjustment will be allowed only under the most extreme circumstances. ${ }^{32}$ However, while the selection of the three days may have important practical consequences for a particular pipeline company, it is far from being the most unsatisfactory aspect of the Atlantic Seaboard formula.

The most disturbing aspect of Atlantic Seaboard is, rather, the arbitrary fifty-fifty allocation of system-wide fixed costs between the demand charge and the commodity charge. That allocation has no justification other than the vague notion that "all gas transported by the pipeline will share in all of the various kinds of expenses incurred to transport the gas." 33 There is no reason to suspect a connection between the amount of the expenses that "should" be borne by a class of consumers and the amount that is allocated to them by the fifty percent approach. Indeed, it is clear from the Boiteaux-Steiner analysis that under some circumstances a class of consumers should clearly not be required to pay any portion of capacity costs. For example, under the conditions represented by Figure 2, requiring the $D_{1}$ users to pay a portion of capacity costs would result in the situation in which gas would not be sold to some consumers willing to pay the full costs of providing it. It is meaningless to comment that they should "pay their share" of the capacity costs, for it is clear that $D_{1}$ consumers demand the gas because the pipeline exists; the pipeline does not exist because they demand the gas. The situation is quite the opposite with respect to $D_{2}$ and $D_{3}$ consumers. In the terms of the graphical analysis, the very nature of the cumulative demand curve

29. See text accompanying notes $41-42$ infra.

30. Knoxville Util. Bd. v. Eastern Tenn. Natural Gas Co., 35 F.P.C. 534, 63 P.U.R.3d 359 (1966). The FPC indicated, however, that the adjustment would not easily be allowed, and actually refused to allow it in the Knoxville case itself. Id. at 538,63 P.U.R.3d at 364.

31. Garfield \& LOVEJOY 184.

32. See note 30 supra.

33. In re Atlantic Seaboard, II F.P.C. 43, 56, 94 P.U.R. (NS) 235, 247 (1952). 
makes it apparent that the $D_{1}$ consumers simply do not have enough demand to justify constructing a plant with capacity of $\bar{x}_{2}=\bar{x}_{3}$. The plant of this size was constructed because the intersection of $D_{C}$ with the MC curve occurred at that point on the graph. The $D_{1}$ curve had ceased to have any effect upon the $D_{C}$ curve long before that point of intersection.

In fairness to the FPC, it must be pointed out that the agency, responding to some of the criticisms of Atlantic Seaboard, ${ }^{34}$ has now indicated severe dissatisfaction with the formula ${ }^{35}$ and has begun to move away from it. One of the ways in which the Commission has sought to shift from a strict application of Atlantic Seaboard is found in American Louisiana Pipe Line Co ${ }^{36}$ In that case, the FPC paid lip service to Atlantic Seaboard by carefully allocating fixed costs between the demand and the commodity charges, and even went to the absurd length of so allocating the costs of storage facilities used exclusively to help satisfy peak demand ${ }^{37}$ However, after going through that allocation, the FPC mitigated its effect by allowing a "deviation toward demand" of thirteen percent in the rate schedule. ${ }^{38}$ Thus, the total demand charge was thirteen percent greater than the costs allocated to that function, and the commodity charge was proportionately less. As a result of this alteration in the price schedule, peak prices would be greater, and off-peak prices less, than they would have been under a strict application of Atlantic Seaboard. The reason given

34. Garfield \& Lovejoy 184-85; Herz, Impact of Cost Allocation on Gas Pricing, 58 PUB. UtIL. ForT. 685 (1965); Wellisz, The Public Interest in Gas Industry Rate Structures, Parts I \& $I I, 70$ PUB. UTIL. FoRT. 65,145 (1962).

35. See, e.g, Knoxville Uitil. Bd. v. Eastern Tenn. Natural Gas Co., 35 F.P.C. 534, 539, 63 P.U.R.3d 359, 365 (1966); In re Great Lakes Gas Transp. Co., — F.P.C. — 69 P.U.R.3d 497, 515 (1967), remanded on other grounds sub nom. Northern Natural Gas Transmission Co. v. FPC, 399 F.2d 953 (D.C. Cir. 1968); In re Midwestern Gas Transp. Co., 34 F.P.C. 973, 98182, 61 P.U.R.3d 241, 251-52 (1965), affd sub nom. Fuels Research Council, Inc. v. FPC, 374 F.2d 842 (7th Cir. 1967); In re United Fuel Gas Co., 31 F.P.C. 1342, 1347, 55 P.U.R.3d 196, 202 (1964); In re American La. Pipe Line Co., 29 F.P.C. 932, 940, 48 P.U.R.3d 321, 330 (1963), rev'd on other grounds, 344 F.2d 525 (D.C. Cir. 1965).

36. 29 F.P.C. 932, 941 , 48 P.U.R.3d 321 (I963), rev'd on other grounds, 344 F.2d 525 (D.C. Cir. 1965).

37. 29 F.P.C. $932,941,48$ P.U.R.3d 321,331 (1963). Inasmuch as storage facilities are built for "peak-shaving" purposes-i.e., in order to reduce the demand for pipeline space during peak periods-and compete with other users for gas during off-peak periods, it seems rather remarkable that the off-peak users should be expected to contribute to the cost of constructing storage facilities. Incredibly enough, the FPC was not unaware of these considerations, but explicitly considered them and still arrived at a decision to allocate the cost of storage facilities.

38. 29 F.P.C. 932, 943-44, 48 P.U.R.3d 321, 334-35 (1963). 
for the deviation was the necessity of lowering prices to industrial users so that gas could compete effectively with other fuels in the industrial market.

To the extent that the approach taken in American Louisiana and similar cases $^{39}$ represents a subsidization of off-peak users by peak users because off-peak users would otherwise not buy gas, then the action taken is entirely appropriate. Indeed, it should not be termed a subsidy, for the price reduction benefits both off-peak users, who pay less, and peak users, who would otherwise bear the full cost of capacity construction. In the terminology of the FPC, the action is appropriate because even though each dollar of commodity charge paid contributes less to fixed costs than it would if the Atlantic Seaboard formula were applied, the percentage of total pipeline revenues consisting of commodity charges is greater than it would otherwise be. The element of fixed costs in the commodity charge is smaller, but the total revenue from commodity charges is greater. The propriety of the American Louisiana approach, assuming it represents a reduction in off-peak prices from the level at which they would be set in the absence of competition, can perhaps best be seen by an example. Assume that firm users will purchase 150 thousand cubic feet (MCF) of gas, that quantity will not change with changes in price within the range relevant to this example, and that interruptible users will purchase $50 \mathrm{MCF}$ if the interruptible rate reflects an allocation of 50 percent of fixed costs, but will purchase $100 \mathrm{MCF}$ if that allocation is reduced to 40 percent. Under these circumstances, firm users will pay 100 percent of the total demand charges and 75 percent of the total commodity charges if 50 percent of fixed costs are so allocated to commodity charges. If, however, only 40 percent of fixed costs are so allocated, so that interruptible users purchase $100 \mathrm{MCF}$, firm users will pay 100 percent of total demand charges and only 60 percent of total commodity charges. ${ }^{40}$ If the decrease in commodity charges paid by firm users as a result of using a 60-40 percent allocation is greater than the increase in the demand charge resulting from the allocation of more fixed costs to that charge, then both firm and

39. See, e.g., In re Midwestern Gas Transmission Co., 34 F.P.C. 973, 61 P.U.R.3d 241 (1965), affd sub nom. Fuels Research Council, Inc. v. FPC, 374 F.2d 842 (7th Cir. 1967).

40. If interruptible users purchase $50 \mathrm{MCF}$, the total amount of gas sold will be $200 \mathrm{MCF}$. Interruptible users will pay $50 / 200$, or $25 \%$, of the total commodity charges. If, however, such users purchase $100 \mathrm{MCF}$, the total amount of gas sold will be $250 \mathrm{MCF}$ and the portion of commodity charges paid by interruptible users will be $100 / 250$ or $40 \%$. 
interruptible users will benefit from using a $60-40$ percent allocation method."

Even though the FPC approach in American Louisiana may benefit all gas consumers, there is no basis for saying that the FPC is taking account of the existing demand curve of industrial users for natural gas. It can only be said that the American Louisiana approach may lead to a price structure that is closer to that which is economically ideal than would the Atlantic Seaboard formula strictly applied. A moment's reflection will reveal, however, that the American Louisiana approach may also indicate that in the absence of competition for gas the FPC is following a policy, not necessarily intentional, of actually requiring that monopoly profits be extracted from industrial users to be used to offset inappropriately low prices for gas destined for household use. ${ }^{42}$ Most of the commentators have implicitly assumed this to be true,,$^{13}$ and if this is in fact the case, it is hard to justify on grounds other than political expediency. ${ }^{44}$ However, no studies have been made which would lead to a conclusion as to the actual role-conscious or otherwise-which has been played by the FPC.

The American Louisiana method of approving a "deviation to demand" is not the only way in which the FPC has been willing to circumvent the doctrine of Atlantic Seaboard. In other cases the FPC has permitted other deviations from the Seaboard formula ${ }^{45}$ including an allocation of costs on a two-thirds/one-third basis. ${ }^{46}$ In light

41. Assuming that industrial sales were made at a price greater than the variable costs associated with those sales (and ignoring the relative scarcity of gas), it is demonstrable that all users benefit from a price structure that enables gas to compete with other fuels for industrial users. Inherent in this analysis are two assumptions. First, it is assumed that there will be a net increase in revenues from industrial sales as a result of the decrease in price. In other words, it is assumed that the price elasticity of demand for industrial gas is greater than unity in the relevant price range. To the extent that industrial users are able to use other fuels if gas is too expensive, and do rapidly switch to other fuels, that assumption is probably justified in many instances. Second, it is assumed that when industrial prices are lowered, there is either no cffcct in other gas markets, or any effects which may occur (such as an increase in the price to firm users) are not of such a magnitude as to offset the incrcase in rcvenues from industrial sales.

42. See note 49 infra.

43. The assumption can be scen in the widely held view that interruptible rates are kept unduly high by the application of the Atlantic Seaboard formula. See, e.g., Garfield a LoveJoy 184-85; Herz, supra note 34; IVellisz, supra note 34.

44. See text following note 49 infra.

45. See, e.g., Midwestern Gas Transmission Co., 34 F.P.C. 973, 61 P.U.R.3d 241 (1965).

46. In re Great Lakes Gas Transp. Co., __ F.P.C. — 69 P.U.R.3d 497, 515 (1967), remanded on other grounds sub nom. Northern Natural Gas Co. v. FPC, 399 F.2d 953 (D.C. Cir. 1968). 
of these cases and of the FPC's expressed dissatisfaction with the Atlantic Seaboard formula ${ }^{47}$ it is probably safe to say that Atlantic Seaboard is no longer good law. So far, however, nothing has replaced it other than the judgment of the FPC - a judgment which is apparently formed with very little regard for considerations other than cost and, only when absolutely necessary, competition. Without estimates of demand conditions, an appropriate determination of prices is highly unlikely. The commissioners' judgment is probably preferable to the Atlantic Seaboard formula, but only because the former is more flexible than the latter. Until steps are taken to ensure that the commissioners' judgment is based upon an appropriate economic analysis of prevailing conditions, there is little likelihood that they will be able to set prices at the economically appropriate levels. ${ }^{48}$

\section{Incentives Provided by the FPC for Pipeline Companies}

Even assuming the Atlantic Seaboard formula no longer has life in it, it has not yet received a formal burial and the FPC still professes to follow it. Furthermore, even if its precise formula has been rejected, there is no indication that the cost-orientation which originally led to its adoption has been abandoned. It is therefore appropriate, in analyzing the effect of FPC regulation upon the incentives of regulated companies, to look to Atlantic Seaboard as representative of the FPC approach. Such an analysis is essential to an understanding and an appraisal of the FPC's work, for the greatest single danger of current FPC regulation probably lies in the incentives for abuse that it provides the pipeline companies.

One of the most important aspects of a rate proceeding today is the allocation of costs between jurisdictional and non-jurisdictional sales. Because this allocation will have a direct effect on the price of jurisdictional gas, but will have no necessary effect on nonjurisdictional prices, there is a clear incentive for pipeline companies to exert efforts to affect the allocation. To the extent that a pipeline can shift costs to jurisdictional users, and thus justify an increase in their rates, it can nullify the ability of the agency to accurately set a price lower than that which would be charged to a profit-maximizing

47. See note 35 supra and accompanying text.

48. See Donahue, supra note 3 , for a discussion of steps which might be taken to cure this problem. 
monopolist. ${ }^{49}$ For example, if the cost-based price of jurisdictional gas is below a company's profit maximization price, the company may be able to shift its price toward the profit maximization price by persuading the FPC to allocate more costs to jurisdictional sales. Since non-jurisdictional sales are not regulated, and therefore will not be cost-determined, the allocation of more costs to jurisdictional sales will have no effect upon the price that can be charged on nonjurisdictional sales. Thus, by securing a heavier allocation of costs to jurisdictional users, the pipeline can obtain higher rates on their gas with no offsetting decrease in rates to non-jurisdictional users.

Furthermore, a pipeline may have an incentive to have a large percentage of costs allocated to the demand charge, rather than to the commodity charge. The commodity charge is paid by both firm-peak and interruptible-off-peak users. The demand charge, on the other hand, is paid by peak users only. Since peak gas is primarily used for

49. The unregulated, profit-maximizing monopolist who is fortunate enough to control a market with the characteristics depicted in Figure 5 will use capacity to the point at which marginal revenue, not shown in Figure 5, equals marginal cost. He will then determine price and capacity use for each customer in a manner closely analogous to the manner shown in Figures 2 and 5 . It is possible, however, that there will be a monopoly as to some sub-markets (such as, for example, the peak use market), but that the other sub-markets (such as the offpeak markets) will be competitive. In that event, it may be expected that the company will, if allowed, act like a monopolist in the markets, or during the periods of time, in which it faces non-competitive conditions. One of the consequences of such a Jekyll-and-Hyde pattern of behavior is that the pipeline company will have put itself in a position such that it can subsidize the competitive market at the expense of the other. Thus, it may be possible for a regulating agency to force a "hidden" subsidy upon a pipeline company by the simple expedient of keeping prices low during the competitive period.

Because regulation may so casily lead to subsidy, particularly when the regulatory jurisdiction does not extend to all users, it is both useful and important to attempt to identify the types of consumers who use gas during different time periods. For the most part, off-peak users are industrial users, while gas which is transported during peak hours is destined for households. See GARFIELD \& LOVEJOY 175-77. Thus, a price structure which subsidizes off-peak users at the expense of peak users will benefit industrial users and will operate as a tax on private individuals. It does not necessarily follow, of course, that a structure should be designed which will subsidize peak users, for there is no apparent reason for individuals who use gas rather than electricity to be given a reward for using gas. Even if off-peak gas users are a group that society desires to tax, and even if peak users are a group that society desires to benefit, there is no necessary reason for using the price structure of gas as a means for transferring funds from one group to the other. Making the price structure serve this additional function renders it far less useful for serving the one function for which it is ideally suited: allocating the most efficient amount of the resource to each of its uses through the relationship of its price to the price of competitive resources. Moreover, loading the subsidy program onto the price structure interferes with the freedom of choice of both the taxed consumer and the subsidized consumer. To the extent that freedom of choice is a positive goal, any interference with it must necessarily be undesirable. 
household needs, it will probably be true, in the short run at least, that an increase in rates will not affect the amount of consumption since households have a demand for fuel which is probably not responsive to price changes, and unlike industrial users, cannot easily change the fuel used. Whether an increase in peak prices at the cost of a decrease in off-peak prices would be profitable in a given case would depend upon the comparative price elasticities of demand for peak and for off-peak users in that case. Moreover, it may be true that a "proper" pricing structure would lead to higher peak prices, and the incentives may therefore have socially desirable consequences. However, it is important to recognize that there will be an incentive to affect the allocation of costs between the demand and the capacity charges; even if regulated prices are too low for peak users, it is not generally sensible to create a regulatory agency and to allow the circumvention of the regulated rates..$^{50}$

Most of the commentators who have analyzed the Atlantic Seaboard formula assume that the formula results in overcharging interruptible users and undercharging firm users. ${ }^{51}$ However, this assumption has not been established by empirical evidence, and what little evidence does exist could be interpreted to suggest that interruptible rates are too low. ${ }^{52}$ First, it appears that in many instances the price of interruptible gas is considerably less, per million BTU, than

50. The mere fact that there may be incentives to affect improperly the cost allocations does not mean that pipeline companies will always attempt to do so.

51. See, e.g., Herz, supra note 34; Nissel, The Impact of Cost Allocations Upon Future of the Natural Gas Industry, 66 PuB. Util. ForTnightly 512 (1960); Ross, How Practical is the Seaboard Formula?, 71 PUB. Util. FortnightL 26 (1963); Weliisz, supra note 34.

52. If the effect of the Atlantic Seaboard formula is that demand charges are set too high, so that firm rates are too high and interruptibie rates are too low, then it follows that peak sales will be less than they would otherwise be. Thus, the tendency will be toward the extraction of a monopoly profit from peak users. However, the existence of those monopoly profits may be very hard to discover. First, it may be hidden because the excess capacity that should result from a reduction in supply to firm users may take the form of a decrease in stored gas. Although excess capacity in a pipeline itself may be observed, it is much harder to determine whether the "right" amount of gas is being put into storage during those periods. A second reason that it may be hard to discover whether monopoly profits are being extracted from firm users is that the pipeline company has an unregulated off-peak market in which it might have monopoly power. Accordingly, the existence of monopoly profits does not itself demonstrate that prices have been set too high in one of the jurisdictional areas. Third, it is not at all easy to determine, in fact, whether monopoly profits are ever being derived. There are simply too many ways in which a monopoly may be enjoyed, such as poor cost control, or excessive leisure on the part of highly paid executives, for the existence of a monopoly to be easily observed. 
the cost of alternative fuels, ${ }^{53}$ even though there are reasons to suggest that gas should be a preferable fuel. If for no other reason than the harmful effect on the environment of burning oil and coal, and the much less harmful effect of burning gas, ${ }^{54}$ one would expect that gas would be fully competitive with coal and oil, even at slightly higher prices. ${ }^{55}$ Another indication that interruptible rates are too low is the recent and rapid expansion of storage facilities built by pipeline companies. ${ }^{56}$ This expansion may suggest that interruptible rates are too low in comparison to firm rates, so that it has become more profitable to store gas during off-peak periods for sale during peak periods than to sell the gas during off-peak periods. But this is not the only conclu-

53. National Coal Association, Steam-Electric Plant Factors 10, 12 (1969). In some instances the comparative figures are quite surprising. In Rockford, Illinois, for examplc, Commonwealth Edison is reported to be able to obtain gas for approximately one-third less cost per million BTU than it can obtain eoal. Id.

54. The environmental advantages of gas as a fuel were brought to public attention in the Spring of 1970 when a group known as the Committee Against Pollution invaded the annual stockholders' meeting of Commonwealth Edison in Chicago and demanded that the utility increase its efforts to halt the pollution of that city's air, much of which is apparently caused by burning relatively high sulphur content coal. See N.Y. Times, April 28, 1970, at 61, col. 1. Even those who would argue against using gas instead of coal for the purpose of producing electricity-and there are a number of sound arguments which lead to the conclusion that gas should not replace coal in that use-concede the environmental advantages of gas. See, e.g., FPC v. Transcontinental Gas Pipe Line Corp., 365 U.S. 1 (1961).

55. This measure is not, taken alone, a reliable basis for conclusions concerning the soundness of present interruptible rates. The figures derived from StEAM-ELECTRIC PLANT Factors are generally for non-jurisdictional sales sinee the gas sales included are those made for the production of electricity and therefore not for resale under the holding of FPC v. Transcontinental Pipe Line Co., 365 U.S. 1 (1961). Since non-jurisdictional rates may bc expected to differ from jurisdictional rates, these figures may be of limited significance. On the other hand, the design of the FPC's jurisdiction is based on the view that competition will limit the price charged to industrial consumers, see text accompanying nete 12 supra; and the FPC is supposed to set the priee of jurisdietional sales at the competitive level. In theory, then, the two rate schedules should be the same, at least in the long run. To the extent that the FPC fulfills its assigned function, the Steam-Electric Plant Factors figures are significant for the present analysis.

56. Interestingly enough, Garfield and Lovejoy suggest that the Atlantic Seaboard formula makes interruptible rates too high, GARFIELD \& LOVEJOY 184, and also document the rapid increase in the use of storage facilities in recent years. Id. at $177-78$. They do not attempt to rationalize the apparent contradiction between the evidence and their conclusion. It is possible that their conelusion is appropriate, for there may be explanations for an increased use of storage other than a price for interruptible gas which is too low relative to the price of firm gas, but it is surprising that they do not even attempt to come to grips with what initially appears to be a contradiction. Possible explanations for an increase in storage facilities are that thcre are exceedingly great prospects for growth in the peak market, or that the competition of other fuels in the off-peak market is so great that it is advantageous to store gas for peak sales rather than reduce the price of off-peak gas to the extent necessary to make gas competitive in that market. 
sion which may be derived from the fact of rapid expansion of storage facilities. 1t is equally plausible that the price of interruptible gas is higher than it should be in relation to other fuels, ${ }^{57}$ so that other fuels control the market, and it is more advantageous for pipeline companies to transport and store gas than to leave the pipeline space idle. It may even be true that there is no possible cost justification for selling interruptible gas. ${ }^{58}$ The reason for the decision to store gas can be determined in a particular case, but cannot be abstractly determined for all cases; accordingly, conclusions cannot be drawn from the mere fact that a considerable amount of gas is being stored.

A different criticism which has been suggested with respect to the Atlantic Seaboard formula is that it may create an incentive for pipeline companies unnecessarily to expand their facilities since the formula expresses the permitted net income as a percentage of a pipeline's capital investment. ${ }^{59}$ Since investment is the source of income, it is possible that companies may attempt to allocate fixed costs to the commodity charge in order to increase interruptible rates and reduce firm rates, thereby encouraging peak use and creating an apparent need for even further expansion. ${ }^{60}$

A final objection to the Atlantic Seaboard approach is the effect of that formula upon high- and low-load factor users. The load factor

57. If demand charges are too Iow, so that interruptible rates are too high and firm rates are too low, the inappropriate determination may be more easily discovered. Such a situation would result in excessive capacity being used during peak hours, and in the existence of substantial unused capacity during off-peak hours. It is likely that excessive quantities of gas would be stored for sale during peak periods. However, these characteristics would not indicate conclusively that firm prices are set too low. The situation may rather be that the off-peak demand for gas is simply not strong enough to justify devoting full capacity to its satisfaction. In terms of the Boiteaux-Steiner model discussed earlier in this article, the demand for interruptible gas may be represented by $D_{1}$ in Figure 2 . In such a case, it would be entirely appropriate to use pipeline capacity to the ultimate extent at all times and to store some gas during off-peak periods for sale during peak periods.

58. That would be true if it were the case that prices which were low enough to be competitive in the interruptible market would be too low in comparison to firm rates to make the sale of interruptible gas profitable. The situation then would be one in which there were two markets in which the company may sell-the present interruptible market and the future firm market.

59. Wellisz, supra note 34 , at 150 .

60. A somewhat different effect of tying income to investment is suggested in Averch \& Johnson, Behavior of the Firm Under Regulatory Constraint, 52 AM. ECON. REv. 1052 (1962). The Averch-Johnson theory is based on the conclusion that allowing a return only on capital will lead to inappropriate substitutions of capital for labor. That problem may be pertinent to FPC decisions, and it might be reduced if a Boiteaux-Steiner approach were adopted. It is not, however, a difficulty which nceds further attention here. 
of a pipeline is the percentage of reserved space in a pipeline that is actually used for the transportation of gas to the consumer who has reserved the space. Thus, it is pertinent only with firm users, since only they have reserved space. Such users pay a demand charge, based upon the space which they have reserved, and a commodity charge, based on the actual amount of gas transported to them. In this situation the allocation of any fixed costs to the commodity charge creates a form of price discrimination to the detriment of high-load-factor users. ${ }^{61}$ Under the Atlantic Seaboard formula, a high-load-factor user will pay a greater percentage of fixed costs than a low-load-factor user because he pays a greater commodity charge, even though the lowload-factor user has the same right to obtain gas and therefore preempts as much of the pipeline capacity.

This aspect of the formula brings out clearly the fundamental unsoundness of the FPC approach, that is, the notion that prices must be derived from an analysis of costs. Since it is true that the consumer who has the right to obtain gas during peak hours, but who uses none, pays only a demand charge, while the interruptible user pays only a commodity charge, it is impossible to arrive at an appropriate price structure if prices are to depend upon where costs are allocated. ${ }^{62}$ In order to charge the low-load-factor customer an appropriate amount for the capacity he preempts, it is necessary to include in the commodity charge no more than the actual variable costs associated with gas transmission. ${ }^{63}$ However, if interruptible users are to pay more than merely the variable costs of gas transmission, as they should whenever their demand leads to full utilization of capacity - such as the $D_{2}$ users in Figure 2-then the commodity charge should include some amount of fixed costs. In that event, however, the off-peak interrupti-

61. Nissel, supra note 51, at 516-17.

62. It will be possible to arrive at such a price structure only if there is but one period during which full capacity is used, so that, as determined under the Boiteaux-Steiner approach, there is no group of users which uses full capacity but pays less than the highest price; in terms of Figure 2, there is no " $\mathrm{D}_{2}$ " group. It is likely, however, that such conditions will not often prevail.

63. It has been observed that a high-load-factor user should pay more than a low-load-factor user per unit of capacity because the "high-load-factor user makes greater average use of a unit of capacity." GaRfield \& Lovejoy 185 n.55. Presumably, the reason for that principle is that there is some doubt as to the accuracy of the measurement of variable costs and a consequent fear that the fixed cost will, as measured, include some charges such as actual wear and tear that are in fact variable. Considerations such as these, which apparently lead Garfield and Lovejoy to accept an approach that might be termed "pragmatic but second best" are ignored here both in order to simplify the analysis and because such an approach is only second best. 
ble users-the $D_{1}$ user in Figure 2-will be charged too much and will purchase less. Clearly these requirements are incompatible and are indicative of the need to abandon the practice of basing prices on costs and to begin, at last, to adopt the Boiteaux-Steiner approach in FPC rate proceedings.

\section{Conclusions: The Need for a New Approach to Gas Pipeline REgULATION}

The approach to peak load pricing established by Boiteaux and Steiner, in the abstract, leads to a logical determination of the appropriate size of pipeline construction and the appropriate prices which should be charged for pipeline products. If there are two periods at which the full capacity of a pipeline is used, the Boiteaux-Steiner solution compels the conclusion that the price to customers during each of those periods should not be the same if the relative contribution to the cumulative demand curve of each of the two separate demand curves is not identical. Rather, the users with the "stronger" demand curve should pay a higher price for the gas sold to them; the price should be higher because it should contain a greater amount of the contribution toward capacity costs. Users whose demand is less strong, but who also require the full use of capacity, should make a lesser contribution to capacity costs. If there is a truly off-peak class of users - as in the $D_{1}$ users in Figure 2-which does not use the full capacity of the pipeline, that group-or, more precisely, the group using the pipeline during that off-peak period-should pay only the variable costs directly associated with providing them service. The prices established in this manner are not necessarily related either to those which would be established by the profit maximizing monopolists or to those which would be established by the FPC under present regulatory procedures. It is conceivable that present procedures lead to the establishment of prices which are lower both than the ideal price and than the price of the profit maximizing monopolists, and it is therefore conceivable that attempts by pipeline companies to influence FPC prices will, in effect, be an attempt to move them towards the ideal level. However, there is no apparent evidence indicating the actual relationship among the three sets of prices, or of the effect of such industry efforts.

It is clear that the framework within which the FPC must operate 
is not as clear or as easily examined as that of the Boiteaux-Steiner model. First, the problem of long-term decreasing marginal and average cost functions compels a solution which differs to some extent from the Boiteaux-Steiner solution unless marginal cost pricing is employed and pipeline companies are externally subsidized. That problem has been examined in depth in the economic literature and need not be re-examined here. The second major distinction between the FPC framework and the Boiteaux-Steiner model is the existence of a non-jurisdictional demand for gas for which prices cannot be regulated. Because that demand exists, the price which is set by the FPC will not necessarily be the price to all consumers during any given time period. Moreover, the Boiteaux-Steiner determined price, which maximizes the excess of expressed consumer satisfaetion over the cost of resources devoted to production may not be the price which will be charged in the unregulated market, since that other market may not be fully competitive and the monopolist will desire to maximize monopoly profits.

Thus, the regulation of prices by the FPC in the manner which is ideal is not an easy chore. Nonetheless, FPC regulation has heret of ore ignored that chore entirely, and there can no longer be any question but that a re-evaluation of its rate-setting procedures is called for. The view that rates should be determined by costs is not inherently unreasonable for an agency that views its function as insuring that monopoly profits are not derived by a regulated company. But such an approach can and does lead to wrong and inconsistent results. ${ }^{64}$ The FPC should instead refer to the costs of a company only to ensure that its rates are not, in fact, allowing monopoly profits. The argument that such an approach will be ineffective because discovery will be made only after the profit has been extracted may be valid under the present law, based on statutory language that a final rate determination cannot be retroactively reappraised if it subsequently appears that the rate determination was too high. ${ }^{65}$ Accordingly, either an amendment to the Act or an unduly broad reading of its fairly restric-

64. See note 37 supra and accompanying text.

65. This is the clear implication of FPC v. Sunray DX Oil Co., 39 I U.S. 9 (1968). But see FPC v. Tennessee Gas Transmission Co.; 371 U.S. 145 (1962). In Sunray, the Court held that under 15 U.S.C. $\$ 717 \mathrm{c}$ (e) (1970), refunds could not be ordered below a rate set in a final, unconditional permanent eertificate. Tennessee Gas involved the easily distinguishable situation of a rate increase initiated pending a determination of reasonableness. 
tive language is called for. The statute should not demand that the FPC have such confidence in its decisions that it be willing to make them irrevocable, for such an approach only encourages too much initial attention to costs. Even so, until such time as the present law is changed, either legislatively or judicially, it would be desirable for the FPC to be willing to take more of a risk.

The appropriate approach to the pricing problem would be that which is suggested by the Boiteaux-Steiner model. Prices should be set in such a manner as to ensure that there is neither excess capacity nor excess demand during any period. The sole exception to that structure should be the situation in which there will be excess capacity unless prices for one group of consumers are set below the variable cost of providing the gas. In that situation, those customers should be charged only the variable costs. During periods in which firm customers are being served, a two-price system should be used to avoid inappropriate discrimination between high- and low-load-factor consumers. This aspect of the needed changes is particularly important, since it is desirable to encourage high-load-factor use, and the present structure does exactly the opposite. ${ }^{66}$

It is clear that a price structure such as that suggested requires that the FPC shift much of its attention away from costs. Such a shift is indeed desirable, for the essence of efficient peak-load pricing is attention to demand. Estimates of the demand curves of various users are vital. Such estimates are, of course, speculative, but not so speculative as to produce inherently less accurate results than the current costallocation approach.

The relationship between costs and revenues need not and should not be ignored. If profits appear excessive under a price structure which seems to eliminate both excess capacity and excess demand, then there is a clear indication that the existing facilities need to be expanded, either through making storage facilities functional or through expanding the pipeline facilities themselves. The appropriate amount of expansion also depends upon economic analysis. In its application to the matter of expansion, however, the Boiteaux-Steiner approach becomes somewhat more speculative and less easily applied. However, it is preferable to alternative means of determining the proper extent of expansion.

66. See GARFIELD \& LoveJoY 185. 
A number of the suggested changes can be accomplished with relative ease. Their effectiveness, however, would be considerably augmented if Congress were to expand the jurisdiction of the FPC to include all sales by natural gas pipelines. ${ }^{67}$ The presence of nonjurisdictional sales clouds the analysis of FPC regulation in too many places to be justified by the fact that competition may exist in the direct sale market. While there might be some difficulties in that market if gas were regulated and other fuels were not, competition between regulated and unregulated fuels is justified by the need to make FPC regulatory activities more easily analyzed and corrected.

These changes require little in the way of actual alteration in FPC operations. ${ }^{68}$ They require that the FPC shift its attention from the approach exemplified by Atlantic Seaboard. but there are indications that the FPC is already dissatisfied with that approach. ${ }^{69}$ They require that the FPC jurisdiction be expanded, which the FPC may not desire, ${ }^{70}$ but that is not a matter which is entirely within the power of the FPC.

67. There may, of course, be some limitations imposed by the commerce clause of the Constitution on the power of Congress to regulate gas rates within a state. However, that constitutional limitation has not hampered Congressional legislation in any significant way in recent years and, in any event, it is clear that FPC jurisdiction could be expanded considerably before any constitutional limitations would be approached.

68. Under the approach suggested by Leslie Cookenboo, L. Cookenboo, Crude OIL Pipe LINES AND COMPETITION IN THE OIL INDUSTRY (1955), the entire structure of the FPC would be different. In essence, that approach involves the notion of regulating pipeline companies only to the extent of requiring that all pipelines be built by joint venturers. Any person willing to pay his share of construction costs would be allowed to become a member of the joint venture. Since some individuals would, presumably, speculate and purchase space in order to satisfy future demand, there would be unused space until that demand arises. Because of the existence of the excess capacity, no monopoly profits would be available, for there would be no monopoly. To some extent, competition between the owners of space would have the same effect when and if the pipeline is ever operating at full capacity. The cause of the natural monopoly is eliminated, since no one pipeline company has economies of scale not shared by its competitors, but there is only the minimum necessary amount of regulation. Furthermore, the risk of regulatory error is virtually non-existent, and the cost of error is shifted from the consumer, who has neither responsibility for making the error nor the means to correct it (but who must bear the cost of it under the present system), to the pipeline company, which has both.

The most serious difficulty with adopting the Cookenboo approach immediately is caused by existing pipeline companies which are not joint ventures. If the regulatory scheme were shifted immediately, it is likely that many pipeline companies would be in a monopolistic position until such time as increased demand was sufficient to provide the incentive for an additional pipeline.

69. Sce note 35 supra and accompanying text.

70. Cf. Phillips Petroleum Co. v. Wisconsin, 347 U.S. 672 (1954). See also Cato, Would You Believe. . . ?, 22 NAT. REv. 505 (1970), indicating both that the FPC is still dissatisfied with the Phillips decision and an unawareness of the history of that case. See Letters, 'TwAS 
If the recommendation that the FPC cure itself of its cost fixation is not followed, then expansion of its jurisdiction becomes even more essential. The allocation of costs is made immensely more difficult by the perceived need to distinguish between jurisdictional and nonjurisdictional costs. If that distinction can be eliminated, there is at least a hope that the approach taken by the FPC will yield results which more closely resemble a proper price structure.

But a Dream, 22 NAT. Rev. 596 (1970). See also Wall Street Journal at 10, col. 1, November 8, 1971 (Eastern ed.). 


$$
\text { . }
$$

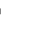

